\title{
MODERN ORTHODONTIA IN PRINCIPLE AND PRAGTICE.*
}

\author{
By W. O. Talbot, D. D.S., Fort Worth, Texas.
}

MODERN orthodontia is that branch of dental science which has for set of teeth. The early practice of orthodontia was devoted to the correction of irregularity of the teeth with little or no regard for correct occlusion. To Edward H. Angle, more than any other man, is due the credit for the change of principle. To E. A. Bogue is also due the credit of teaching and practicing the prevention of irregularities of the permanent teeth by the expansion of the arches of the temporary teeth.

There are two great principles that control the practice of orthodontia. The first is to establish function of the teeth; the second is to establish harmony in the facial lines. The primary function of the teeth is mastication of food, and this can best be performed when the teeth are in normal occlusion, so the ideal in every case of orthodontia should be to establish the most perfect occlusion possible. To do this correctly one must study the plaster casts of a case until he has pictured in his mind the shape, size, and relative position of the arches and the exact position of each tooth in its relation to every other tooth in both arches.

All malpositions and disproportions must be compared with the normal in order to determine the extent of the abnormality. To do this is to diagnose the case. To tell or to write the diagnosis of a case of maloccluison is to classify it. The only classification in orthodontia that will ever stand and be universally accepted must be based on the relation of the jaws, the dental arches, and the position of the individual teeth. Orthodontia is based on occlusion, therefore its classification of malocclusion must be in accordance with occlusal relations.

The classification of Angle is the only one so far in use that is founded on this system. He divides all cases into three great classes. Those with a normal mesio-distal relation of the arches he calls Class I. Those with a distal relation of the lower arch he calls Class II, and divides the Class into Divisions 1 and 2, with a subdivision each for the unilateral cases in each division. Those with a mesial relation he calls Class III, and makes a subdivision of this in unilateral cases. This is the best that has been done and all praise and honor should be given for the advances, and yet it is open to criticism because malocclusion is a deformity and as such should have a name that indicates the deformity. Lischer has offered a classification based on the malformation of the jaws, malrelation of the derital arches, and malposition of the teeth which is an improvement, in some respects, over the Angle classification, though it is not perfect. Other writers have offered classifications based on dento-facial relations and have numbered the classes, but these have not been accepted by the profession. Some writers have divided irregularities into groups or divisions according to the tooth move-

*Read before the Texas State Dental Association, at Ft. Worth, April, 1914. 
ment required for correction. Such grouping is not a classification in any sense, for most cases would belong to several classes at the same time.

In order to diagnose a case correctly, as a rule, the following procedure should be gone through. At the first sitting the case should be examined and the parent, or guardian, who accompanies the child on the first few visits should be informed of the nature and requirements of orthodontia treatment in the presence of the child, unless he or she is familiar with such work. The parent should also be advised of the usual expense of such work, but with few exceptions, no price should be made for a given case until the casts of the case have been studied. Consultation fees should be charged when casts are made, a diagnosis made, price of treatment given, and the work is not done. If there are deposits of tartar, the teeth should be scaled and polished before impressions are taken. In all cases the impressions should be taken in plaster. Have the trays deep enough to carry the plaster well around the alveolus so as to show the position and direction of the roots of the teeth and the thickness of the process. Plaster casts should be made from the impressions and carved as usual in nice regular form.

If there are delayed unerupted teeth, with no indications of their presence, and particularly if the space is partly closed up, skiagraphs should be made to determine positively their absence or presence and the location. If there is much facial deformity, as in distal or mesial occlusion cases or in open-bite and excessive over-lap cases with lip displacement, the front and profile photos should be made and kept as a record of the case, likewise this should be done when such cases are completed. In some cases it is difficult to determine just how much an arch varies from the normalwhether too wide or to narrow for the size of the teeth and the jaws. This part of the diagnosis has been greatly simplified by the use of the celluloid charts and instrument devised by $\mathrm{C}$. A. Hawley, by the use of which the central, lateral, and cuspid may be measured and the average size and shape of that arch determined. The use of this chart is not absolute in all cases out it is a good average and should be in use by every man who practices brthodontia.

It has long been a mooted question among certain prominent writers as to whether one arch of teeth was too far mesial or the other too far distal, or whether both arches were abnormal in relation to the contour of the profile. In Angle's Class II and Class III cases this point frequently has to be decided in order to make a correct diagnosis. A correct occlusion is determined by the normal cusp locking, but facial harmony is the anatomical balance of the features in profile in which the three artist's divisions of the face-the upper, the middle and the lower thirds, are in correct relation each with the other two, according to type. To determine this relation is the work of an artist, to correct the mal-relation is art itself. No mathematical rule absolutely controls art, but there are well recognized proportions in the human anatomy, and particularly in the face, that constitute beauty. It is said that in a correct Greek type of face a perpendicular line will touch the brow, pass through the middle of the wing of the nose, through the lower part of the upper lip and touch the lower lip and chin. This rule does not apply to the Roman type of face.

After making a great many tests, the writer has found that the following 
rule of harmony will apply in most cases of both types and to their combinations; viz., taking the anterior border of the external meatus of the ear, which is one of the earliest calcifications and constant points of the head, as the center of the circle: the tip of the chin, the tip of the nose and the middle of the forehead should be in the circumference, also that the incisal edges of the upper centrals and the bridge of the nose between the eyes should be in the circumference of a circle with the same center. These measurements can be taken of the face with a compass prepared for the purpose. When a diagnosis has been made, it should be written out in full and a record made of every and each variation from the normal. This should be kept for frequent reference in conjunction with the original casts, photos, and skiagraphs.

The next step is the mental process of seeing the teeth of a given case moved about in the jaws, the arches of teeth expanded or contracted, the teeth extruded or retruded, rotated, or the relation of the arches shifted until all the teeth assume their correct relation in their respective arch, and the arches stand in correct relation to each other and the facial lines are harmonized. This is the process which reverses the abnormality, and is necessary in order to plan the correct treatment. It enables one to decide what appliances should be used, how they should be set, and how the force should be applied to produce the required movement, and what anchorage should be secured to withstand the pressure.

In planning treatment one should never forget that he is shaping, making, and remodeling human anatomy, that he is dealing with living tissue.

In considering the appliance to be used every form of appliance, every alteration, and every retainer should be planned and a record made of it before treatment begins. When a case is once thoroughly mastered and definite plans laid and recorded for the treatment, the case will require but little further study.

The next point to consider is the time required to correct a case, and the time the retainers should be worn. This can only be determined by the experience of the operator, and others who have handled similar cases of like age and with similar appliances, but an approximation should be made and recorded. The case may take a few months or a few years, but the patients want to know, and should know.

The next step in the process is to fix a fee for the work and the terms of payment. This should be agreed upon and recorded and a payment secured before treatment is begun. This clause may seem out of place in a scientific paper, but it is a science that few dentists put into practice, and this is where it belongs - just before the work begins. If it is not considered here it will be the first time you say money, and if you happen to be able to wait until the case is finished to say it, nine times out of ten you will take less than your time and services are worth, or make an everlasting enemy of the patient and perhaps both. If a dentist is undecided as to the exact charge to make, he should name a maximum and a minimum fee. These things should be put into a contract form and signed, or at least agreed to by the parties financially responsible.

Treatment in orthodontia consists principally in tooth movement by the application of force to the crowns of the teeth, by the use of appliances 
to move them into arch alignment and correct occlusal relations. In open bite cases and in Class III cases, the force may be appllied to the chin. Anchorage for the application of this force is in the teeth of the same arch, teeth of the opposite arch, and the occipital anchorage supplied by the use of the head gear. Tooth movement takes place by tipping, in which the crown moves further than the apex of the root and vica versa, and by bodily movement in which the crown and the root move in parallel lines. These comprise the four movements of mesial, distal, buccal, and lingual. In addition there is rotation, elongation and depression in which all parts of the tooth move alike.

Nearly all cases of irregularity require some expansion, most of which is needed in the anterior part of the arch. It is often difficult to determine the best appliance to use in a given case as so to get the best results in the shortest time and under the conditions affecting the handling of the case. The basic appliance in Orthodontia work requiring the expansion is the "Expansion Arch" or "Arch Bar", which may be modified into many forms and used with many attachments to great advantage.

Every orthodontist owes it to himself and to his patients to study carefully the merits of the various forms and qualities of the material of which appliances are made. The best way to study appliances and materials is by using them. The greatest advance in orthodontia appliances in recent years has been in the new Angle appliances for moving the anterior teeth bodily.

Another valuable modification of the arch is the use of a finger spring soldered to the arch and allowed to rest on the labial surfaces of the anterior teeth to prevent tipping, or the use of a U-shaped wire attached to the arch and resting across the anterior teeth for the same purpose.

Then comes a most valuable modification known as the loop attachment which is an oval pin soldered to each end of the arch wire and resting in a tube soldered to the molar band parallel to the long axis of the tooth. The pin is held in place by a loop spring soldered to the arch. By the use of this attachment in conjunction with Angle's new pins and tubes on the bicuspids and the anterior teeth, the entire arch may be expanded by moving the teeth bodily, while each tooth is under control to be moved more or less as desired. This has never been possible before with any appliances. The greatest objection to this appliance is the necessity of banding each tooth to which it is applied. Retainers may be constructed on this plan to great advantage. 